Research Article

\title{
Firms' Strategic Pricing and Network Externalities
}

\author{
Jianheng Zhou ${ }^{1}$ and Rongfei Xu $\mathbb{D}^{1,2}$ \\ ${ }^{1}$ Glorious Sun School of Business \& Management, Donghua University, Shanghai 200051, China
}

${ }^{2}$ Taizhou College, Nanjing Normal University, Taizhou 225300, China

Correspondence should be addressed to Rongfei Xu; xrf@nnutc.edu.cn

Received 2 October 2019; Revised 13 December 2019; Accepted 17 January 2020; Published 18 February 2020

Academic Editor: Alessio Ishizaka

Copyright (c) 2020 Jianheng Zhou and Rongfei Xu. This is an open access article distributed under the Creative Commons Attribution License, which permits unrestricted use, distribution, and reproduction in any medium, provided the original work is properly cited.

\begin{abstract}
For the sale of a product with network externalities, a Stackelberg model involving an incumbent and an entrant is developed considering the impact of three strategic decision-making modes of the incumbent and consumers on the pricing, market share, and profit of firms. In addition, the impact of consumers' strategic behaviours on firms' pricing decisions and how firms respond to strategic customers is discussed. The results show that, in the SS (strategic firm facing strategic consumers) decision-making mode, the incumbent will implement long-term pricing and finally obtain the maximum profit, while as a follower of the incumbent, the entrant will also obtain the maximum profit in the SS mode. In the NS (nonstrategic firm facing strategic consumers) decision-making mode, the strategy of consumers seriously weakens the decision-making behaviour of the incumbent and causes the incumbent to obtain the lowest profit, but at the same time, the competitiveness of the entrant is enhanced to a certain extent, thereby rendering its profit higher than that in the NN (nonstrategic firm facing nonstrategic consumers) decisionmaking mode.
\end{abstract}

\section{Introduction}

"Network externality" is an important concept that was introduced by Western economists in the mid-1980s. Network externality is mainly used to analyse the demand characteristics of information technologies and network products. Katz and Shapiro [1] first referred to "positive consumption externality" as "network externality," referring to the value of connecting to a network depending on the number of other people connected to the same network. Generally, each user obtains utility from using a product, which is related to the total number of users, i.e., the more users that there are, the more utility that each user attains. The value of each person in the network is proportional to the number of others in the network; that is, the larger the network scale of the product is, the more obvious the externality economy. When the network scale exceeds a certain value, the network externality will increase sharply; for example, in fixed telephone networks, the number of users determines the number of network connection lines; when new users are added, new network connection lines are added and the use value of the original users is also increased, thus providing direct externalities to all other users in the network. In two-way communication networks, whether tangible (such as fax machine and telephone networks) or intangible (such as the network of e-mail users and instant messaging systems), products and services with direct network externalities are typical. In a communications network, users join the same network because they want to be in direct contact with each other. In recent years, studies on network externalities have successively emerged. Bensaid and Lesne [2], Doganoglu [3], Li and Chen [4], Hajji et al. [5], Bayer and Chan [6], and Li et al. [7] studied the dynamic pricing problem under network externality. They introduced the network externality intensity coefficient to characterize the size of the network externality so that the network externality can be used for strategic pricing. This paper will also use this approach to describe network externalities. Subsequently, domestic and foreign scholars have carried out extensive studies on network externalities. Jing et al. [8], Aoyagi et al. [9], Mouakket and Sun [10], and Xu [11] have mainly focused on the optimal pricing of goods with 
network externalities. Choi and Lee [12] studied the impact of network externalities on compatible goods. This paper will discuss the impact of network externalities on commodity pricing through the Hotelling model.

Firms usually only consider the maximization of their own interests in the pricing decision-making process, and the strategic behaviours of consumers are less involved. However, with the popularization of information technology and the improvement of education, consumers are becoming increasingly "smart" and can obtain historical data on firm sales through various means. Based on these historical data, consumers will make different strategic responses and choose the right time to buy the goods that they prefer at sufficiently low prices. Bountali and Economou [13], Elmaghraby and Keskinocak [14], and Liu and Huangpei [15] have referred to consumers waiting to buy at a low price as "strategic consumers" and the inverse as "myopic consumers." Myopic consumers do not consider the future price and will make purchases as long as the current price is lower than their reserve price. Such behaviour enables retailers to ignore the influence of future price reductions on current consumers' purchases. However, strategic consumers will consider future price changes when making current decisions, thus leading to more complex current price decisions of manufacturers. Aviv and Pazgal [16] found that if retailers ignore consumers' strategic waiting behaviours, their income will be reduced by nearly $30 \%$. Therefore, the behaviour of strategic consumers is attracting increasing attention from manufacturers. Among investigations of strategic consumer behaviour, Tiebo et al. [17] have studied how firms can improve their profits through strategic decisions; Surasvadi et al. [18] considered profiting from strategic consumers by lowering prices; Wei and Zhang [19] studied a new advance selling strategy to counter strategic consumer behaviour. This paper also discusses consumers' strategies through a two-stage Hotelling model and studies how firms respond to consumers' strategic behaviours through cross-cycle pricing strategies.

Based on the above research, this paper uses the duopoly market as its background, following Colombo [20] and Liu et al. [21]. A model of two firms entering the market successively in two stages is established, and a Stackelberg game is played between the incumbent and the entrant. On the premise of introducing network externalities, this paper discusses the impact of consumers' strategic behaviours on firms' pricing decisions and how firms respond to strategic customers. Few studies have focused on the interaction between consumers' and firms' strategies. Whitin [22], Young and Price [23], Polatoglu [24], Federgruen and Heching [25], and Dana and Petruzzi [26] have focused on nonstrategic pricing and nonstrategic consumers. Bernard and Lesne [2] and Li et al. [7] have considered the problem of two-stage pricing but only considered the current earnings of the first stage when making first-stage pricing decisions, thereby ignoring its influence on future earnings; that is, the firms in this literature have implemented nonstrategic pricing.

In the sales of products with network externalities, the practices of firms in many industries show cooperation and mutual influence between the early and late strategies of firms and consumers. To analyse the mechanism and study the influence of the strategic behaviours of firms and consumers regarding competitive decision-making, this paper assumes that firms and consumers have the following three decision-making modes. The first is the decision-making mode of nonstrategic firms facing nonstrategic consumers $(\mathrm{NN})$; that is, in two-stage pricing decision-making, the incumbent realizes the profit maximization of two single stages, consumers are short-sighted and will not consider the future price, and as long as the current price is lower than their reserve price, they will make a purchase. The second is the decision-making mode of nonstrategic firms facing strategic consumers (NS). That is, the incumbent still implements nonstrategic pricing to maximize profits in two single stages, but this time, consumers make strategic decisions (in the first stage, they weigh the following three decisions: they buy the products of the incumbent in the first stage; they buy the products of the incumbent in the second stage; or they buy the products of the entrant in the second stage). At the same time, they choose the right time to buy their favourite goods at a sufficiently low price. The third is the decision-making mode of strategic firms facing strategic consumers (SS), in which the incumbent implements crosscycle strategic pricing to maximize total profits in two stages, while consumers still make strategic decisions. Among them, $\mathrm{NN}$ and NS are the benchmark models of SS, and there is a progressive relationship between these three models. By comparing these three decision-making models, this paper illustrates how firms can make full use of network externalities to implement a cross-cycle pricing strategy in response to consumers' strategic behaviour to maximize profits.

The strategies of firms and consumers and the network externality coefficient are found to affect the pricing, market share, and profit of two firms in two stages. Compared with the NN mode, the strategy of consumers in the NS mode seriously weakens the competitive advantage of the incumbent and causes the incumbent to obtain the lowest profit; however, at the same time, the competitiveness of the entrant is enhanced to a certain extent, rendering its profit higher than that in the NN decision-making mode. In the SS decision-making mode, the incumbent conducts long-term pricing and ultimately obtains the maximum profit, while as a follower of the incumbent, the entrant will also obtain the maximum profit in the SS mode.

\section{Illustration and Timing of the Model}

Suppose that two firms, 1 and 2, are located at end points 0 and 1 , respectively, of a Hotelling unit line $x \in[0,1]$ and compete on price. The two firms, respectively, provide products $A$ and $B$, which are homogeneous except for the location difference. Both products have the same positive network externality, and the coefficient is $\alpha$. Without loss of generality, the marginal costs of product $A$ and product $B$ are assumed to be zero.

Suppose that a consumer population with unit mass is uniformly distributed along the unit interval $[0,1]$ and that each consumer has only one unit of product demand in the 
entire sales cycle (this paper assumes that there are two stages in one cycle). The distances of consumers from the two firms $x$ can be regarded as their different preferences for the two products as consumers choose which product to buy and when to buy it, according to their preferences. Thus, when the consumer at $x$ buys product $i$ at price $p_{i}$, $i \in\{A, B\}$, following Li et al. [7] and Cao et al. [27]; the product's value for a consumer is determined by two factors: the intrinsic value of the product, $v-p_{i}-t x$, and the increase in product value due to network externalities, $\alpha Q_{i}$. Accordingly, the total utility that the consumer receives is $U_{i}=v-p_{i}-t x+\alpha Q_{i}$, where $v$ is the direct value or utility of the product to consumers, and has nothing to do with network externality; $Q_{i}$ is the market share of product $i ; \alpha Q_{i}$ represents the additional value caused by network externality; $t$ is the unit transport cost; and $t=1$ is assumed for simplified analysis.

The two firms play games in two stages over the whole sales cycle. The game timing is shown in Figure 1. In the first stage, firm 1 enters the market alone and is located at the left endpoint 0 of a linear city $[0,1]$; it provides product $A$ and conducts monopolistic pricing at what is called the monopoly stage. In the second stage, firm 2 also enters the market and is located at the right endpoint 1 of the linear city; it provides product $B$ and competes as an oligopoly with firm 1 based on the first stage in what is called the competition stage. The game timing is as follows: firm 1 (strategic or nonstrategic) decides its pricing $p_{A 1}$ in the first stage, while nonstrategic consumers decide whether to buy in the first stage according to $p_{A 1}$. Strategic consumers have three choices at this time: buy product $A$ in the first stage; buy product $A$ in the second stage; or buy product $B$ in the second stage. Strategic consumers weigh these three options and decide whether to buy in the first stage. In the second stage, firm 2 enters the market and competes with firm 1 for the remaining market; at the same time, firm 2 decides on price $p_{B 2}$ on the basis of the second-stage pricing $p_{A 2}$ first announced by firm 1 in the first stage. Consumers delaying purchases will decide between firm 1 and firm 2 . Because the second stage is the last stage, consumers cannot wait any longer, so the decision-making behaviour of strategic consumers and nonstrategic consumers is the same.

This paper assumes that the whole game process is information symmetric and that consumers can predict whether a new product will enter the market and choose the product with the greatest utility. According to the backward induction method, we first consider the competitive pricing of two firms in the second stage and then consider the pricing of the first stage of firm 1 in three decision-making modes: NN, NS, and SS.

\section{Firm Competition Stage Pricing Decision}

The competition stage, namely, the second stage, is the last stage of the game; therefore, whether strategic or not, the firm's decision-making is aimed at maximizing single-stage revenue and the decision-making behaviours of strategic consumers and nonstrategic consumers are the same. At this point, firm 2 enters the market and competes for the remaining market share with firm 1 , which is already present in the market, causing the market situation to change from a complete monopoly to a competitive oligopoly. Firm 1 reprices its products to realize profit maximization in the second stage. Firm 1 announces price $p_{A 2}$ first, then firm 2 sets price $p_{B 2}$ according to $p_{A 2}$, and then the two firms play a Stackelberg game.

After firm 2 enters the market, consumers delaying purchases will decide between firm 1 and firm 2 . If the market is completely covered, then the utility obtained by the consumer located in $x_{2} \in[0,1]$ when purchasing product $A$ is $U_{A 2}=v+\alpha x_{1}-p_{A 2}-x_{2}$, where $x_{1}$ is the market share of firm 1 in the first stage, and the utility obtained by purchasing product $B$ is $U_{B 2}=v-p_{B 2}-\left(1-x_{2}\right)$. The consumer is indifferent in regard to buying $A$ or $B$ if his or her $x_{2}$ is such that $U_{A 2}=U_{B 2} ;$ therefore, $x_{2}=\left(1-p_{A 2}+p_{B 2}+\alpha x_{1}\right) / 2$. In Theorem 2, we prove that $x_{2}>x_{1}$, so the quantity demanded for products $A$ and $B$ is $x_{2}-x_{1}$ and $1-x_{2}$.

In the second stage, firm 1 makes its pricing decision first, firm 2 sets the price of product $B$ according to firm 1's decision, and then firm 1 and firm 2 play a Stackelberg game. Therefore, according to the backward induction method, the income optimization problem of firm 2 is first solved as follows:

$$
\underset{p_{B 2}}{\operatorname{Max} \pi_{B 2}}=p_{B 2}\left(1-x_{2}\right) .
$$

By solving equation (1), the pricing function of firm 2 can be obtained as $p_{B 2}^{*}\left(p_{A 2}\right)=\left(1+p_{A 2}-\alpha x_{1}\right) / 2$ and $x_{2}$ is $x_{2}^{*}\left(p_{A 2}\right)=\left(3-p_{A 2}+\alpha x_{1}\right) / 4$. The following is used to solve the revenue maximization problem of firm 1 . The optimal revenue problem of firm 1 in the second stage is as follows:

$$
\underset{p_{A 2}}{\operatorname{Max} \pi_{A 2}}=p_{A 2}\left[x_{2}^{*}\left(p_{A 2}\right)-x_{1}\right] .
$$

By solving equation (2), the optimal pricing of the two firms in the second stage and the corresponding income in the corresponding stage can be obtained, as shown in Proposition 1.

Proposition 1. Given firm 1's market share in the first stage $x_{1}$,

(1) The optimal pricing, market share, and revenue of firm 1 in the second stage are $p_{A 2}^{*}=[3-(4-\alpha)$ $\left.x_{1}\right] / 2, \Delta x_{A 2}^{*}=\left[3-(4-\alpha) x_{1}\right] / 8$, and $\pi_{A 2}^{*}=[3-(4-$ a) $\left.x_{1}\right]^{2} / 16$, respectively

(2) The optimal pricing and revenue of firm 2 in the second stage are $p_{B 2}^{*}=\left[5-(4+\alpha) x_{1}\right] / 4$ and $\pi_{B 2}^{*}=$ $\left[5-(4+\alpha) x_{1}\right]^{2} / 32$, respectively

By observing the pricing of the two firms in the second stage, we know that $\partial p_{B 2}^{*}\left(p_{A 2}\right) / \partial p_{A 2}=1 / 2>0$; that is, $p_{B 2}^{*}\left(p_{A 2}\right)$ increases with $p_{A 2}$. When firm 1 raises its price, firm 2, as firm 1's follower in the second stage, also has the opportunity to raise its price; however, the price increase of firm 2 is only half that of firm 1 , showing the advantage of market pioneers.

As seen from $x_{2}^{*}\left(p_{A 2}\right)=\left(3-p_{A 2}+\alpha x_{1}\right) / 4, x_{2}^{*}\left(p_{A 2}\right)$ is the decreasing function of $p_{A 2}$ and the increasing function of 


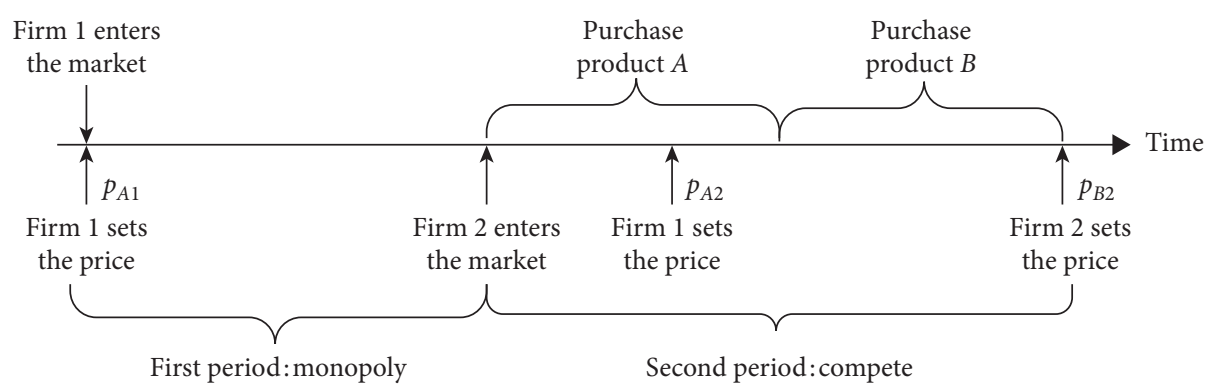

Figure 1: Timing of the two-stage market entry game.

$\alpha, x_{1}$, so firm 1 can expand its total market share in both stages by reducing price $p_{A 2}$ and expanding its market share $x_{1}$ in the first stage to enhance its competitiveness with firm 2 .

Proposition 1 (1) shows that $p_{A 2}^{*}, \Delta x_{A 2}^{*}$, and $\pi_{A 2}^{*}$ are all decreasing functions of $x_{1}$; that is, the larger the market share $x_{1}$ in the first stage is, the smaller the pricing $p_{A 2}^{*}$, market share $\Delta x_{A 2}^{*}$, and profit $\pi_{A 2}^{*}$ of firm 1 in the second stage. This occurs because if $x_{1}$ is larger, consumers delaying purchases move farther away from firm 1 in the second stage and if they buy product $A$, they will pay more transport costs. Coupled with the entry of firm 2 in the second stage, the consumer makes a trade-off between buying products $A$ and $B$, and firm 2 has an absolute advantage in terms of reducing transportation costs. Combined with the above factors, the market share of firm 1 in the second stage $\Delta x_{A 2}^{*}$ will be smaller. At this time, firm 1 can only obtain a certain market share and earn a lower profit by lowering its price.

Proposition 1 (2) shows that both $p_{B 2}^{*}$ and $\pi_{B 2}^{*}$ are decreasing functions of $\alpha, x_{1}$; that is, the greater the value $\alpha x_{1}$ added to product value due to externalities is, the greater the opportunity for firm 1 to expand its market share. In contrast, firm 2 will gain a smaller market share, so firm 2 can only lower its price and obtain a smaller profit.

Because of the existence of network externalities, the sales volume $x_{1}$ of firm 1 in the first stage will affect the earnings of the two firms in the second cross stage. Therefore, it is very important for firm 1 to make an intelligent pricing decision in the first stage and to determine the sales volume in the monopoly stage. From another perspective, firms must consider how to determine the sales volume in the first stage and then consider pricing in the first stage, which will also affect the income in the first stage; therefore, firm 1 will face a trade-off of how to distribute the income of the two stages in the monopoly stage.

\section{Firm 1's Monopoly Stage Pricing Decision}

Based on the above two firms' competition stage solutions, this section further considers the pricing strategy of firm 1 in the first stage, namely, the monopoly stage, and the strategic choices of consumers. Since the pricing $p_{A 1}$ of firm 1 in the first stage and the strategic choices of consumers affect the sales volume $x_{1}$ in the first stage, they might also affect the competitive situation in the second stage. Whether firm 1 considers these factors in the first stage cannot be ignored in its pricing decision. To reflect the influence of the strategic decision-making mode on the competitive situation of both sides, this section is divided into three modes in the monopoly stage.

\subsection{The Decision-Making Mode of a Nonstrategic Firm Facing} Nonstrategic Consumers (NN). For the sake of comparison, this section first considers the benchmark model of a nonstrategic firm facing nonstrategic consumers when it monopolizes the market in the first stage. In this case, firm 1 only pursues single-stage profit maximization in the first stage when making monopolistic pricing decisions and consumers will not foresee the purchase opportunity in the second stage. In this paper, superscript $N$ represents the pricing decision situation of a nonstrategic firm facing nonstrategic consumers.

If the utility that a consumer obtains at $x_{1} \in[0,1]$ when he buys product $A$ is $U_{A 1}=v-p_{A 1}-x_{1}$, then the boundary customer who obtains the same utility between buying and not buying is $x_{1}=v-p_{A 1}$ given $U_{A 1}=v-p_{A 1}-x_{1}=0$, and consumers on the left of $x_{1}$ will choose the first stage to buy product $A$. Therefore, the market share obtained by firm 1 in the first stage is $x_{1}$, and its single-stage optimal revenue in the monopoly stage is as follows:

$$
\underset{p_{A 1}}{\operatorname{Max} \pi_{A 1}}=p_{A 1}\left(v-p_{A 1}\right)
$$

By solving equation (3), all market equilibrium values of the two firms in both stages under the NN decision-making mode can be obtained, as shown in Proposition 2.

Proposition 2. Under the NN decision-making mode, the optimal pricing, maximum market share, and corresponding optimal returns of the two firms are as follows:

(1) The first stage of firm 1: $x_{1}^{N}=v / 2, p_{A 1}^{N}=v / 2$ and $\pi_{A 1}^{N}=v^{2} / 4$

(2) The second stage of firm 1: $p_{A 2}^{N}=u_{\alpha} / 4, \pi_{A 2}^{N}=u_{\alpha}^{2} / 64$, $x_{2}^{N}=(6+4 v+v \alpha) / 16, \quad \Delta x^{N}=u_{\alpha} / 16, \quad$ and $\pi_{A}^{N}=v^{2} / 4+u_{\alpha}^{2} / 64$, among them $u_{\alpha}=6-4 v+\alpha v$ and $u_{\alpha}>0$

(3) The second stage of firm 2: $p_{B 2}^{N}=(10-4 v-v \alpha) / 8$ and $\pi_{B 2}^{N}=(10-4 v-v \alpha)^{2} / 128$

According to Proposition 2 (1), when $x_{1}^{N}=v / 2=1$, that is, $v=2$, the market is completely covered. In this case, $p_{A 1}^{N}=x_{1}^{N}=\pi_{A 1}^{N}=1$. To enable firms 1 and 2 to continue to compete for the remaining market share in the second stage, 
let us say that $x_{1}^{N}<1 / 2$; that is, $v \leq 1$. However, the value of $v$ cannot be too small; otherwise, the market in the second stage cannot be completely covered. Therefore, we set $v=[4 / 5,1]$. According to Proposition 2 (2), under the NN decisionmaking mode, with the increase in the network externality coefficient, the pricing, market share, and profit of firm 1 will increase in the second stage, while that of firm 2 will decrease. According to Proposition 2 (3), the larger the network externality, the smaller the market share of firm 2, and at this point, the price can only be reduced to obtain a smaller profit.

\subsection{The Pricing Decision-Making Mode of a Nonstrategic Firm} Facing Strategic Consumers (NS). This section further discusses the decision-making mode of a nonstrategic firm 1 confronted by strategic consumers when it monopolizes the market in the first stage. Similar to Section 4.1, in this case, firm 1 still only pursues single-stage profit maximization in the first stage when setting monopolistic prices in the first stage and consumers no longer decide whether to buy based on consumer surplus but weigh the following three options: purchase product $A$ in the first stage; purchase product $A$ in the second stage; or purchase product $B$ in the second stage. Currently, consumers' strategies directly affect the pricing decisions of the two firms. In this paper, the superscript NS is used to represent the pricing decision situation of a nonstrategic firm facing strategic consumers. We ignore the time discount, which will not change the result that we want.

At this point, the utility of the consumer at $x_{1}$ under the three decisions is as follows: $U_{A 1}=v-p_{A 1}-x_{1}$, $U_{A 2}=v+\alpha x_{1}-p_{A 2}-x_{1}$, and $U_{B 2}=v-p_{B 2}-1+x_{1}$.

The conditions of purchase $A$ in the first stage: $\left\{\begin{array}{l}U_{A 1}>0 \\ U_{A 1}>U_{A 2} \\ U_{A 1}>U_{B 2}\end{array}\right.$ solution: $\left\{\begin{array}{l}x_{1}<v-p_{A 1} \\ x_{1}<\left(p_{A 2}-p_{A 1}\right) / \alpha \\ x_{1}<\left(p_{B 2}-p_{A 1}+1\right) / 2\end{array}\right.$.

Suppose $V_{0}=v-p_{A 1}, V_{11}=\left(p_{A 2}-p_{A 1}\right) / \alpha$, and $V_{12}=$ $\left(p_{B 2}-p_{A 1}+1\right) / 2$, so the market share in the first stage is $x_{1}=\min \left\{V_{0}, V_{11}, V_{12}\right\}$. Because $V_{0}$ is the share of nonstrategic consumers in the first stage, $v-p_{A 1}$ is the largest of the three, so $x_{1}=\min \left\{V_{11}, V_{12}\right\}$. Let the values of $V_{11}$ and $V_{12}$ in equilibrium be $V_{11}^{\mathrm{NS}}$ and $V_{12}^{\mathrm{NS}}$, respectively; then, we have the following Proposition 3 for the value of $x_{1}$.

Proposition 3. In NS decision-making mode, $V_{11}^{N S}<V_{12}^{N S}$; that is, the market share in the first stage is as follows: $x_{1}=V_{11}^{N S}$.

In Proposition 3, consumers located in $V_{11}$ see no difference between product $A$ in the first stage and product $A$ in the second stage and consumers located in $V_{12}$ see no difference between product $A$ in the first stage and product $B$ in the second stage. Consumers in $V_{11}$ buy the same product $A$ in both stages without a difference, requiring a small transportation cost, while consumers in $V_{12}$ buy products $A$ and $B$ in both stages without differences, which should be farther away from firm 1 , and the purchase of product $A$ requires a larger transportation cost. As evident in the expression $V_{11}=\left(p_{A 2}-p_{A 1}\right) / \alpha$, consumers' strategic decisions are influenced not only by the first-stage pricing $p_{A 1}$ but also by the second-stage pricing $p_{A 2}$. The larger $p_{A 2}$ is and the smaller $p_{A 1}$ is, the larger $V_{11}$ is; that is, the smaller the pricing of the first stage and the larger the pricing of the second stage, the greater the number of consumers who will be attracted to the first stage, and vice versa. At the same time, we can see that, when $p_{A 2}<p_{A 1}$, firm 1 has no market share in the first stage; that is, the pricing in the second stage is less than that in the first stage and consumers rush to the second stage for consumption. By substituting $x_{1}=\left(p_{A 2}-p_{A 1}\right) / \alpha$ into the decision-making parameters in the second stage of Proposition 1 , all of the market equilibrium values in the two stages of firms 1 and 2 can be obtained, as shown in Proposition 4 .

Proposition 4. Under the NS decision-making mode, the optimal pricing, maximum market share, and corresponding optimal benefits of the two firms are as follows:

(1) The first stage of firm 1: $x_{1}^{N S}=3 /(12+\alpha)$, $p_{A 1}^{N S}=3 \alpha /(12+\alpha)$, and $\pi_{A 1}^{N S}=9 \alpha /(12+\alpha)^{2}$

(2) The second stage of firm 1: $x_{2}^{N S}=9 /(12+\alpha), p_{A 2}^{N S}=$ $6 \alpha /(12+\alpha), \pi_{A 2}^{N S}=36 \alpha /(12+\alpha)^{2}, \pi_{A}^{N S}=45 \alpha /(12+$ $\alpha)^{2}$, and $\Delta x^{N S}=6 /(12+\alpha)$

(3) The second stage of firm 2: $p_{B 2}^{N S}=2(3+\alpha) /(12+\alpha)$ and $\pi_{B 2}^{N S}=2(3+\alpha)^{2} /(12+\alpha)^{2}$

According to Proposition 4, the decision variables $x_{1}^{\mathrm{NS}}$, $x_{2}^{\mathrm{NS}}$, and $\Delta x^{\mathrm{NS}}$, which are related to market share in the two stages of firm 1 , are all decreasing functions of $\alpha$. $\partial p_{A 1}^{\mathrm{NS}} / \partial \alpha>0, \partial p_{A 2}^{\mathrm{NS}} / \partial \alpha>0, \quad \partial \pi_{A 1}^{\mathrm{NS}} / \partial \alpha>0, \quad \partial \pi_{A 2}^{\mathrm{NS}} / \partial \alpha>0$, and $\partial \pi_{A}^{\mathrm{NS}} / \partial \alpha>0$; that is, the two-stage pricing and profit of firm 1 are both increasing functions of $\alpha$. Because firm 1 makes nonstrategic decisions and consumers make strategic consumption decisions in the NS decision-making mode, the larger the externality coefficient $\alpha$ is, the more that the strategic consumer foresees that the externality will increase the value of product $A$ in the second stage; therefore, the purchase decision is delayed until the second stage, resulting in the reduction of market share $x_{1}$ in the first stage. However, firm 1 foresees that it has little hope of attracting consumers by lowering prices, which will also result in lower profits in the first stage. To maximize the profit in the first stage, it makes full use of the monopoly position to implement the high-price mechanism. In the second phase, $x_{1}$ will affect the decision across the cycle. When $x_{1}$ decreases, the value $\alpha x_{1}$ added to product $A$ due to externalities will not be large, and coupled with the entry of firm 2 in the second phase to compete with it, since consumers are closer to firm 2, the purchase of firm 2's products will save consumers much money, leading to a certain degree of customer loss, while the market share tends to decrease for firm 1 . To maximize its single-cycle profit in the second stage, firm 1 has little hope of attracting customers by lowering its price; therefore, firm 1 continues to implement the high-price mechanism by relying on its advantage of first entry. In other words, the larger the externality coefficient $\alpha$, the lower the market share of firm 1 will be due to the consumers' strategy. To maximize its two stage, single-cycle profit, nonstrategic firm 1 makes full use of its advantage of first entry and 
implements the high-price mechanism in both stages to obtain a larger total profit in the two stages. Firm 2 will gain a larger market share, and $\partial p_{B 2}^{\mathrm{NS}} / \partial \alpha>0$ and $\partial \pi_{B 2}^{\mathrm{NS}} / \partial \alpha>0$; that is, firm 2 , as the following firm in the second stage, also has the opportunity to raise its price to obtain greater profits.

Compared with the NN decision-making mode, for firm 1 in the NS decision-making mode, there is the following theorem.

Theorem 1. Under the two decision-making modes of NN and NS, for firm 1,

(1) Market share satisfies $x_{1}^{N S}<x_{1}^{N}$ and $\Delta x^{N S}>\Delta x^{N}$; when $p_{\alpha}>0, x_{2}^{N S}<x_{2}^{N}$

(2) Pricing satisfies $p_{A 2}^{N}>p_{A 2}^{N S}$; when $q_{\alpha}>0, p_{A 1}^{N S}<p_{A 1}^{N}$

(3) Profit satisfies $\pi_{A 1}^{N S}<\pi_{A 1}^{N}, \pi_{A 2}^{N}<\pi_{A 2}^{N S}$, and $\pi_{A}^{N}>\pi_{A}^{N S}$

Among them, $p_{\alpha}=48 v+6 \alpha+16 v \alpha+v \alpha^{2}-72$ and $q_{\alpha}=12 v-6 \alpha+v \alpha$.

As shown in Theorem 1, compared with the NN decision-making mode, in the NS decision-making mode, due to the strategic consumption of consumers in the first stage, the three decisions are weighed, resulting in a smaller market share of firm 1 in the first stage. In other words, when $x_{1}^{\mathrm{NS}}<x_{1}^{N}$, firm 1 can only attract consumers by lowering prices, as shown in Figure $2(\mathrm{~b}), p_{A 1}^{\mathrm{NS}}<p_{A 1}^{N}$, which finally results in a smaller profit in the first stage, i.e., $\pi_{A 1}^{N S}<\pi_{A 1}^{N}$. Because $x_{1}^{\mathrm{NS}}$ will affect the decision of firm 1 in the second stage across the cycle, at this point, the value-added $\alpha x_{1}^{\mathrm{NS}}$ in the value of product $A$ due to externalities will decrease. The second stage is the last stage, and waiting is no longer an option for consumers; at this point, firm 1 can lower its price to attract consumers, i.e., $p_{A 2}^{N}>p_{A 2}^{\mathrm{NS}}$. At the same time, because the consumers delaying purchases are closer to firm 1 , the purchase of product $A$ in the second stage requires lower transportation costs, leading to the expansion of market share in the second stage, that is, $\Delta x^{\mathrm{NS}}>\Delta x^{N}$. Finally, firm 2 will have higher profits in the second stage, i.e., $\pi_{A 2}^{N}<\pi_{A 2}^{N S}$; however, the overall market share of the two stages still shows a decreasing trend, as shown in Figure 2(a): $x_{2}^{\mathrm{NS}}<x_{2}^{N}$. Finally, the total profit of the two stages is reduced, i.e., $\pi_{A}^{N}>\pi_{A}^{N S}$; in other words, the strategy of consumers seriously weakens the decision-making behaviour of firm 1 , resulting in less profit under NS.

Compared with the NN decision-making mode, in the NS decision-making mode for firm 2 , there is the following theorem.

Theorem 2. Under the two decision-making modes of NN and NS, for firm 2, (1) pricing satisfies $p_{B 2}^{N S}<p_{B 2}^{N}$ and (2) profit satisfies the following relation: when $p_{\alpha}>0, \pi_{B 2}^{N S}>\pi_{B 2}^{N}$.

In Theorem 1, we saw that compared with the NN decision mode, in the NS decision mode, firm 1 expands the market by attracting consumers through price reduction in the second stage and firm 2, as the follower of firm 1, can only reduce its price without the opportunity to increase its price, that is, $p_{B 2}^{\mathrm{NS}}<p_{B 2}^{N}$. However, in the NS mode, the twostage market share of firm 1 decreases due to consumers' strategy. By contrast, firm 2 will gain more market share and thus more profit, as shown in Figure 2(a): $\pi_{B 2}^{\mathrm{NS}}>\pi_{B 2}^{N}$.

4.3. The Pricing Decision-Making Mode of a Strategic Firm Facing Strategic Consumers (SS). This section further discusses the decision-making mode of strategic firm 1 facing strategic consumers when it monopolizes the market in the first stage. Similar to Section 4.2, consumers still make strategic consumption decisions; at the same time, firm 1 adjusts twostage pricing according to consumers' strategies and finally maximizes total two-stage profit, while the strategies of consumers directly affect the pricing decisions of the two firms. In this paper, the superscript $S$ represents the decision-making situation of a strategic firm facing strategic consumers.

In SS decision-making mode, the market share in the first stage is very similar to Proposition 3, and Proposition 5 can be obtained as follows.

Proposition 5. In SS decision-making mode, $V_{11}^{S}<V_{12}^{S}$; that is, the market share in the first stage is as follows: $x_{1}=V_{11}^{S}$.

Similar to Proposition 3, in both the NS and SS decisionmaking modes, consumers make strategic consumption decisions and will choose the option with the greatest utility to them in the first stage.

In the NN and NS decision-making modes, firm 1 makes nonstrategic decisions and only considers the single-period utility maximization of each stage. In the SS decisionmaking mode, firm 1 makes long-term pricing decisions and ultimately realizes profit maximization in the whole cycle. By substituting $x_{1}=\left(p_{A 2}-p_{A 1}\right) / \alpha$ into the decision-making parameters of the second stage in Proposition 1, we can see that the total profit of firm 1 in both stages is the decisionmaking objective function of $p_{A 1}$ which is as follows:

$$
\pi_{A}^{*}\left(p_{A 1}\right)=p_{A 1} \frac{3 \alpha-(4+\alpha) p_{A 1}}{8 \alpha}+\frac{\left(3 \alpha+(4-\alpha) p_{A 1}\right)^{2}}{64 \alpha}
$$

In formula (4), the first term is the income of firm 1 in the first stage and the second term is the income of firm 1 in the second stage. $p_{A 1}$ affects the whole-cycle earnings across cycles. From the discussion of Proposition 6 below, we obtain $\alpha=[4 / 3,2]$. The larger $p_{A 1}$ is, the larger the payoff in the second stage and the smaller the payoff in the first stage; however, since the profit expression for the second stage is a quadratic function of $p_{A 1}$ and the profit expression for the first stage is a linear function of $p_{A 1}$, if firm 1 implements the high-price mechanism in the first stage, namely, increases $p_{A 1}$, it will obtain greater profits in the second stage and smaller profits in the first stage. Therefore, when firm 1 implements the high-price mechanism in the first stage, it can increase its two-stage total income. By contrast, if firm 1 implements the low-price mechanism in the first stage, that is, reduces $p_{A 1}$, although its profit in the first stage will increase and its profit in the second stage will decrease, for the same reason, only a small amount of profit will be increased in the first stage, while in the second stage, more profits will be 


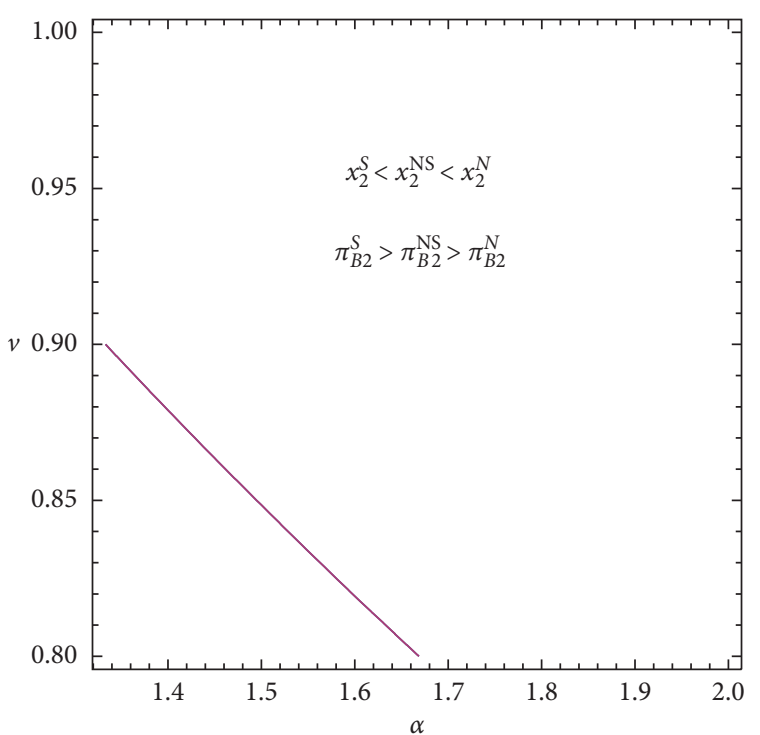

(a)

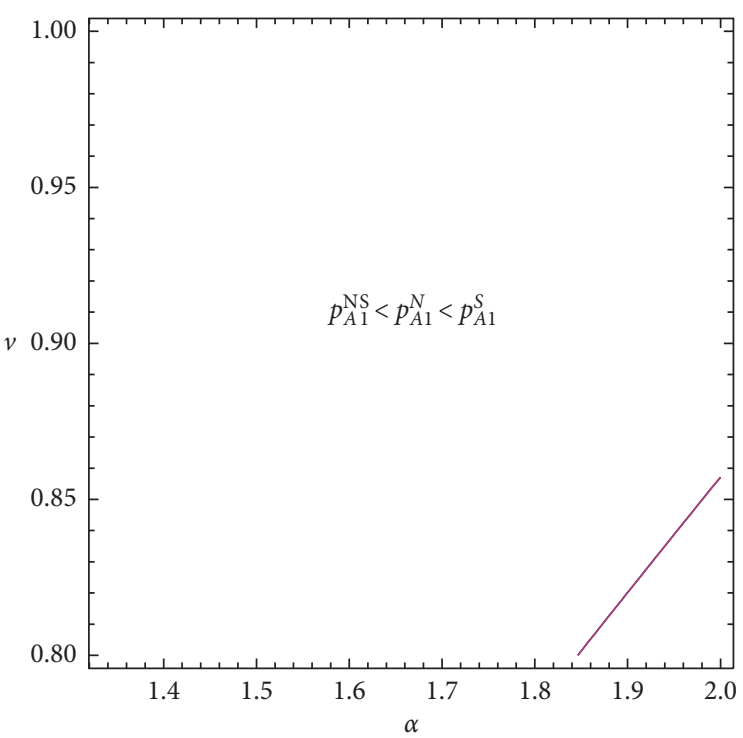

(b)

FIgURE 2: Comparison of market share and pricing in the first stage of firm 1 and the profit of firm 2 under the three modes.

reduced, resulting in a lower total profit across both stages. Therefore, at this time, firm 1 can change its decision about monopoly pricing for future earnings, as shown in Proposition 6.

Proposition 6. Under the SS decision-making mode, the optimal pricing, maximum market share, and corresponding optimal benefits of the two firms are as follows:

(1) The first stage of firm 1: $x_{1}^{S}=(9 \alpha-12) / 2 v_{\alpha}$, $p_{A 1}^{S}=3(8-\alpha) \alpha / v_{\alpha}$, and $\pi_{A 1}^{S}=9(8-\alpha) \alpha(3 \alpha-4) /$ $2 v_{\alpha}^{2}$; among them, $v_{\alpha}=16+16 \alpha-\alpha^{2}$ and $v_{\alpha}>0$

(2) The second stage of firm 1: $x_{2}^{S}=6(2+\alpha) / v_{\alpha}$, $p_{A 2}^{S}=3 \alpha(12+\alpha) / 2 v_{\alpha}, \pi_{A 2}^{S}=9 \alpha(12+\alpha)^{2} / 4 v_{\alpha}^{2}, \Delta x^{S}=$ $3(12+\alpha) / 2 v_{\alpha}$, and $\pi_{A}^{S}=45 \alpha\left(16+16 \alpha-\alpha^{2}\right) / 4 v_{\alpha}^{2}$

(3) The second stage of firm 2: $p_{B 2}^{S}=2\left(4+10 \alpha-\alpha^{2}\right) / v_{\alpha}$ and $\pi_{B 2}^{S}=2\left(4+10 \alpha-\alpha^{2}\right)^{2} / v_{\alpha}^{2}$

Proposition 6 (1) obtains the market share $x_{1}^{S}$ of the first stage in the SS mode, and we obtain $\alpha>4 / 3$ from $x_{1}^{S}>0$. However, the value of $\alpha$ cannot be too large; otherwise, firm 1 will expand to a large market share in the second stage due to externalities, causing firm 2 to occupy a small market share; therefore, we set $\alpha=[4 / 3,2]$.

Proposition 6 obtains the market share, pricing, and profit equilibrium values of firms 1 and 2 in two stages under the SS mode. At this time, firm 1 implements strategic long-term pricing to maximize profits in two stages. At the same time, consumers also make strategic decisions in the first stage, and three decisions are weighed, which will have a new impact on the pricing decision of firm 1. Compared with the NS decision-making mode, the strategic influence of firm 1 and that of consumers on firm 1 are shown in Theorem 3.
Theorem 3. In the two decision-making modes of NS and SS, for firm 1,

(1) Market share satisfies $x_{1}^{S}<x_{1}^{N S}, \quad x_{2}^{S}<x_{2}^{N S}$, and $\Delta x^{S}>\Delta x^{N S}$

(2) Pricing satisfies $p_{A 1}^{S}>p_{A 1}^{N S}$ and $p_{A 2}^{S}>p_{A 2}^{N S}$

(3) Profit satisfies $\pi_{A 1}^{S}<\pi_{A 1}^{N S}, \pi_{A 2}^{N S}<\pi_{A 2}^{S}$, and $\pi_{A}^{S}>\pi_{A}^{N S}$

Like the discussion in formula (4), in the SS decisionmaking mode, firm 1 will implement the high-price mechanism in both stages to maximize its profits in the whole cycle, with $p_{A 1}^{S}>p_{A 1}^{\mathrm{NS}}$ and $p_{A 2}^{S}>p_{A 2}^{\mathrm{NS}}$. At this time, the market share tends to decrease and the profit in the first stage is lower; that is, $x_{1}^{S}<x_{1}^{\mathrm{NS}}, x_{2}^{S}<x_{2}^{\mathrm{NS}}$, and $\pi_{A 1}^{S}<\pi_{A 1}^{\mathrm{NS}}$. At the same time, because the market share in the first stage is smaller, consumers delay purchases closer to firm 1, decreasing the transportation cost of products $A$ purchased in the second stage and then increasing the market share in the second stage; that is, $\Delta x^{S}>\Delta x^{\mathrm{NS}}$. At the same time, the highprice mechanism is implemented in the second stage, causing the profit of the second stage to increase more and finally increasing the total profit of the two stages; that is, $\pi_{A 2}^{\mathrm{NS}}<\pi_{A 2}^{S}$ and $\pi_{A}^{\mathrm{NS}}<\pi_{A}^{S}$.

Compared with the NS decision-making mode, the strategic influence of firm 1 and consumers on firm 2 is shown in Theorem 4.

Theorem 4. Under the two decision-making modes of NS and SS, for firm 2, (1) pricing satisfies $p_{B 2}^{S}>p_{B 2}^{N S}$ and (2) profit satisfies $\pi_{B 2}^{S}>\pi_{B 2}^{N S}$.

From Theorem 3, we have seen that firm 1 implements the high-price mechanism in both stages in the SS decisionmaking mode and firm 2, as the follower of firm 1, also has the opportunity to raise its price; that is, $p_{B 2}^{S}>p_{B 2}^{\text {NS }}$. At the 
same time, the market share of firm 1 decreases over two stages. By contrast, the market share of firm 2 will increase, eventually leading to greater profits; that is, $\pi_{B 2}^{S}>\pi_{B 2}^{\mathrm{NS}}$.

Furthermore, under the three decision-making models, there are two inferences about the market share and the pricing and profit of the two firms.

Corollary 1. Under the three decision-making modes of NN, NS, and SS, for firm 1,

(1) Market share satisfies $x_{1}^{S}<x_{1}^{N S}<x_{1}^{N}$ and $\Delta x^{S}>\Delta$ $x^{N S}>\Delta x^{N}$; when $p_{\alpha}>0, x_{2}^{S}<x_{2}^{N S}<x_{2}^{N}$

(2) Pricing satisfies $p_{A 2}^{N}>p_{A 2}^{S}>p_{A 2}^{N S}$; when $q_{\alpha}>0$, $p_{A 1}^{N S}<$ $p_{A 1}^{N}<p_{A 1}^{S}$

(3) Profit satisfies $\pi_{A 1}^{S}<\pi_{A 1}^{N S}<\pi_{A 1}^{N}, \pi_{A 2}^{N}<\pi_{A 2}^{N S}<\pi_{A 2}^{S}$, and $\pi_{A}^{S}>\pi_{A}^{N}>\pi_{A}^{N S}$

Corollary 1 (1) implies that firm 1 implements the highprice mechanism in the first stage in the SS decision-making mode, thus making its market share the smallest. In the NS decision-making mode, due to the consumers' strategy, the market share also tends to decrease, that is, $x_{1}^{S}<x_{1}^{\mathrm{NS}}<x_{1}^{N}$ and $x_{2}^{S}<x_{2}^{\mathrm{NS}}<x_{2}^{N}$, as shown in Figure 2(a). However, the second stage market share has the opposite trend, that is, $\Delta x^{S}>\Delta x^{\mathrm{NS}}>\Delta x^{N}$

Corollary 1 (2) implies that, considering the consumers' strategy, firm 1 will implement the low-price mechanism in both stages in the NS mode. Combined with the discussion of Corollary 1 (1), the pricing relationship of firm 1 under the three models can be obtained; that is, in Figure 2(b), $p_{A 1}^{N S}<p_{A 1}^{N}<p_{A 1}^{S}$. In the second stage, in the NN decisionmaking mode, because both firm 1 and consumers make nonstrategic decisions to maximize the single-stage profits, firm 1 can take advantage of its pre-existing advantages and will have the maximum room for price increases. Combined with Theorem 3 (2), the second-stage pricing relationship of firm 1 in the three decision-making modes can be obtained, that is, $p_{A 2}^{N}>p_{A 2}^{S}>p_{A 2}^{\mathrm{NS}}$.

Corollary 1 (3) implies that, to achieve the maximum profit for the whole cycle, firm 1 implements the high-price mechanism in the first stage, resulting in minimum market share, thus minimizing the profit in the SS decision-making model. However, in the second stage, the profit is greatly increased, finally causing the total profit across both stages to be the highest. In the NS decision-making mode, due to the consumers' strategy, some consumers decide to consume in the second stage. As a result, the profit in the first stage tends to decrease, while the profit in the second stage tends to increase, finally rendering the total profit across both stages higher than that in the NN decision-making mode.

Corollary 2. Under the three decision-making modes of NN, $N S$, and SS, for firm 2, (1) pricing satisfies $p_{B 2}^{S}>p_{B 2}^{N}>p_{B 2}^{N S}$ and (2) profit satisfies the following relationship: when $p_{\alpha}>0$, $\pi_{B 2}^{S}>\pi_{B 2}^{N S}>\pi_{B 2}^{N}$.

In Corollary 1, we have obtained the relationship between the market share of firm 1 under the three decision-making modes: $x_{2}^{S}<x_{2}^{\mathrm{NS}}<x_{2}^{N}$; that is, under the SS decision-making model, firm 1 gains the minimum market share, while firm 2, by contrast, gains the maximum market share, thus affording it the opportunity to raise the price and thereby obtain the maximum profit. Combined with Theorem 2, we obtain the relationship of firm 2's pricing and profits under the three decision modes, that is, $p_{B 2}^{S}>p_{B 2}^{N}>p_{B 2}^{N S}$; in Figure 2(a), $\pi_{B 2}^{S}>\pi_{B 2}^{\mathrm{NS}}>\pi_{B 2}^{N}$.

\section{Conclusion}

This paper mainly discusses the two-stage game model of products entering the market under three decision modes. Considering the impact of the three strategic decision-making modes of the incumbent and consumers on the pricing, market share, and profit of two firms, we discuss the impact of consumers' strategic behaviours on firms' pricing decisions and how firms respond to strategic customers. To maximize profits in two cycles, the incumbent will make strategic pricing decisions according to consumers' strategies and consumers will have a strategic response to the future pricing of firms based on historical data and will choose the correct time to buy the goods that they prefer at a sufficiently low price. The research shows that the incumbent carries out long-term pricing, thus rendering its total profit highest under the SS decision-making mode. At the same time, due to the cross-cycle strategy of the incumbent, the competitiveness of the entrant is enhanced and its profit is the highest under the SS mode compared with the other two decision-making modes. In other words, the SS decision-making mode enables both firms to achieve a win-win situation. In the NS decision-making mode, the strategy of consumers seriously weakens the decision-making behaviour of the incumbent and causes the incumbent to obtain the lowest profit; however, the entrant's competitiveness is enhanced and its profit is higher than it is under the NN decision-making mode.

This paper studies the two-stage duopoly market entry model, which can help the incumbent and the entrant to provide pricing decisions that maximize profits. In the future, we could further study the multistage and multioligopoly competition models under the considerations of firms' and consumers' strategies.

\section{Appendix}

Proof of Proposition 1: by solving equation (2), we have $p_{A 2}^{*}=\left[3-(4-\alpha) x_{1}\right] / 2, x_{2}^{*}=\left[3+x_{1}(4+\alpha)\right] / 8, \Delta x_{A 2}^{*}=x_{2}$ $-x_{1}=\left[3-(4-\alpha) x_{1}\right] / 8, \pi_{A 2}^{*}=p_{A 2}^{*} \Delta x_{A 2}=\left[3-(4-\alpha) x_{1}\right]^{2}$ /16, $\quad p_{B 2}^{*}=\left[5-(4+\alpha) x_{1}\right] / 4$, and $\pi_{B 2}^{*}=p_{B 2}^{*}\left(1-x_{2}^{*}\right)=$ $\left[5-(4+\alpha) x_{1}\right]^{2} / 32$.

Proof of Proposition 2: by solving equation (3), we have $p_{A 1}^{N}=v / 2, x_{1}^{N}=v-p_{A 1}^{N}=v / 2$, and $\pi_{A 1}^{N}=v^{2} / 4$; substituting $x_{1}^{N}=v / 2$ into Proposition 1 yields $\Delta x^{N}=u_{\alpha} / 16, x_{2}^{N}=$ $(6+4 v+v \alpha) / 16, \quad p_{A 2}^{N}=u_{\alpha} / 4, \quad \pi_{A 2}^{N}=u_{\alpha}^{2} / 64, \quad p_{B 2}^{N}=(10-$ $4 v-v \alpha) / 8$, and $\pi_{B 2}^{N}=(10-4 v-v \alpha)^{2} / 128$, as $4 / 5<v<1$ and $u_{\alpha}=6-4 v+\alpha v>0$.

Proof of Proposition 3: as a proof by contradiction, if $x_{1}=V_{12}=\left(p_{B 2}-p_{A 1}+1\right) / 2$, then substituting $x_{1}=\left(p_{B 2}-\right.$ $\left.p_{A 1}+1\right) / 2$ into Proposition 1 obtains $x_{2}=[(2+\alpha)(1+$ 
$\left.\left.p_{B 2}\right)-\alpha p_{A 1}-2 p_{A 2}\right] / 4$. The profit of firm 2 is $\pi_{B 2}=$ $p_{B 2}\left[1-\left((2+\alpha)\left(1+p_{B 2}\right)-\alpha p_{A 1}-2 p_{A 2}\right) / 4\right]$.

By solving this equation, we have $p_{B 2}^{*}=(2-\alpha+$ $\left.\alpha p_{A 1}+2 p_{A 2}\right) / 2(2+\alpha), x_{2}^{*}=\left(6+\alpha-\alpha p_{A 1}-2 p_{A 2}\right) / 8, x_{1}^{*}=$ $\left[6+\alpha-(4+\alpha) p_{A 1}+2 p_{A 2}\right] / 4(2+\alpha)$, and $x_{2}^{*}-x_{1}^{*}=(6 \alpha+$ $\left.\alpha^{2}-\alpha^{2} p_{A 1}-2 \alpha p_{A 2}+8 p_{A 1}-8 p_{A 2}\right) / 8(2+\alpha)$.

Firm 1's profit in the second stage is $\pi_{A 2}=p_{A 2}((6 \alpha+$ $\left.\left.\alpha^{2}-\alpha^{2} p_{A 1}-2 \alpha p_{A 2}+8 p_{A 1}-8 p_{A 2}\right) / 8(2+\alpha)\right)$.

By solving this equation, we have $p_{A 2}^{*}=\left(6 \alpha+\alpha^{2}+\right.$ $\left.8 p_{A 1}-\alpha^{2} p_{A 1}\right) / 4(4+\alpha), x_{1}^{*}=\left(48+26 \alpha+3 \alpha^{2}-(24+16 \alpha+\right.$ $\left.\left.3 \alpha^{2}\right) p_{A 1}\right) /(8(2+\alpha)(4+\alpha))$, and $x_{2}^{*}-x_{1}^{*}=(\alpha(6+\alpha)-(-8+$ $\left.\left.\alpha^{2}\right) p_{A 1}\right) /(16(2+\alpha))$.

Firm 1's profit in the first stage is $\pi_{A 1}=p_{A 1} x_{1}^{*}\left(p_{A 1}\right)=$ $p_{A 1}\left(\left(48+26 \alpha+3 \alpha^{2}-\left(24+16 \alpha+3 \alpha^{2}\right) p_{A 1}\right) /(8(2+\alpha)(4+\right.$ $\alpha)))$.

By solving this equation, we have $p_{A 1}^{*}=(48+26 \alpha+$ $\left.3 \alpha^{2}\right) /\left(2\left(24+16 \alpha+3 \alpha^{2}\right)\right), \quad p_{A 2}^{*}=\left(384+496 \alpha+216 \alpha^{2}+\right.$ $\left.42 \alpha^{3}+3 \alpha^{4}\right) /\left(8(4+\alpha)\left(24+16 \alpha+3 \alpha^{2}\right)\right), \quad p_{B 2}^{*}=(1152+$ $\left.1200 \alpha+392 \alpha^{2}+30 \alpha^{3}-3 \alpha^{4}\right) /(8(2+\alpha)(4+\alpha)(24+16 \alpha+$ $\left.\left.3 \alpha^{2}\right)\right)$, and $x_{1}^{*}=\left(48+26 \alpha+3 \alpha^{2}\right) /\left(8\left(8+6 \alpha+\alpha^{2}\right)\right)$ and $\left(p_{A 2}^{*}-\right.$ $\left.p_{A 1}^{*}\right) / \alpha=\left(-384-112 \alpha+64 \alpha^{2}+30 \alpha^{3}+3 \alpha^{4}\right) /(8 \alpha(4+\alpha)$ $\left.\left(24+16 \alpha+3 \alpha^{2}\right)\right)$. Because $\forall \alpha \in[4 / 3,2],-384-112 \alpha+$ $64 \alpha^{2}+30 \alpha^{3}+3 \alpha^{4}<0$, and $\left(p_{A 2}^{*}-p_{A 1}^{*}\right) /(\alpha)<0$, this outcome is contradictory and $x_{1}=V_{11}$.

Proof of Proposition 4: firm 1's profit in the first stage is $\pi_{A 1}=p_{A 1} x_{1}=p_{A 1}\left(p_{A 2}-p_{A 1}\right) / \alpha$.

Firm 1's profit in the second stage is $\pi_{A 2}=$ $p_{A 2}\left(x_{2}-x_{1}\right)=p_{A 2}\left[\left(3-p_{A 1}\right) / 4-\left(p_{A 2}-p_{A 1}\right) / \alpha\right]$. By solving this equation, we have $p_{A 1}^{\mathrm{NS}}=3 \alpha /(12+\alpha), \quad p_{A 2}^{\mathrm{NS}}=$ $6 \alpha /(12+\alpha)$, and $x_{2}=\left(1-p_{A 1}+p_{B 2}\right) / 2$.

At this point, the profit of firm 2 is $\pi_{B 2}=p_{B 2}$ $\left[1-\left(1-p_{A 1}+p_{B 2}\right) / 2\right]$, and by solving this equation, we have $p_{B 2}^{\mathrm{NS}}=2(3+\alpha) /(12+\alpha), \quad x_{2}^{\mathrm{NS}}=9 /(12+\alpha), \quad x_{1}^{\mathrm{NS}}=3 /$ $(12+\alpha), \quad \pi_{A 2}^{\mathrm{NS}}=36 \alpha /(12+\alpha)^{2}, \quad \pi_{A 1}^{\mathrm{NS}}=9 \alpha /(12+\alpha)^{2}, \quad \pi_{A}^{\mathrm{NS}}=$ $45 \alpha /(12+\alpha)^{2}, \quad \pi_{B 2}^{\mathrm{NS}}=2(3+\alpha)^{2} /(12+\alpha)^{2}, \quad$ and $\quad \Delta x_{2}^{\mathrm{NS}}=$ $x_{2}^{\mathrm{NS}}-x_{2}^{\mathrm{NS}}=6 /(12+\alpha)$.

Proof of Theorem 1:

(1) $x_{1}^{N}-x_{1}^{\mathrm{NS}}=(12 v+v \alpha-6) /(2(12+\alpha))$; because $4 / 5<$ $v<1, \quad 12 v+v \alpha-6>0, \quad x_{1}^{N}-x_{1}^{\mathrm{NS}}>0 ; \quad x_{2}^{N}-x_{2}^{\mathrm{NS}}=$ $p_{\alpha} /(16(12+\alpha))$, when $p_{\alpha}>0, x_{2}^{N}>x_{2}^{\mathrm{NS}} ; \Delta x^{\mathrm{NS}}-$ $\Delta x^{N}=(96-(12+\alpha)(6-4 v+\alpha v)) /(16(12+\alpha))$ because $4 / 3<\alpha<2,4 / 5<v<1$, and $(12+\alpha)(6-$ $4 v+\alpha v)<14[6-4(4-2) / 5]=61.6<96$;

$\Delta x^{\mathrm{NS}}>\Delta x^{N}$

(2) $p_{A 1}^{N}-p_{A 1}^{\mathrm{NS}}=q_{\alpha} /(2(12+\alpha))$, when $q_{\alpha}>0, p_{A 1}^{N}>p_{A 1}^{\mathrm{NS}}$; $p_{A 2}^{N}-p_{A 2}^{N S}=\left(72-48 v-18 \alpha+8 v \alpha+v \alpha^{2}\right) /(4(12+$ $\alpha)$ ) when setting $f(v, \alpha)=72-48 v-18 \alpha+8 v \alpha+$ $v \alpha^{2}$ and $f_{v}^{\prime}(v, \alpha)=8 \alpha+\alpha^{2}-48<f_{v}^{\prime}(2, \alpha)=-28$. Therefore, $f(v, \alpha)=72-48 v-18 \alpha+8 v \alpha+v \alpha^{2}$ is decreasing with respect to $v$ and $f(v, \alpha)>$ $f(1, \alpha)=24-10 \alpha+\alpha^{2}$, and when $4 / 3<\alpha<2$ and $f(1, \alpha)=24-10 \alpha+\alpha^{2}>0, f(v, \alpha)>0$ and $p_{A 2}^{N}>$ $p_{A 2}^{N S}$

(3) $\pi_{A 1}^{N}-\pi_{A 1}^{\mathrm{NS}}=\left(144 v^{2}-36 \alpha+24 v^{2} \alpha+v^{2} \alpha^{2}\right) /(4(12+$ $\left.\alpha)^{2}\right)$; setting $g(v, \alpha)=144 v^{2}-36 \alpha+24 v^{2} \alpha+v^{2} \alpha^{2}$ and $g_{\alpha}^{\prime}(v, \alpha)=2\left(v^{2} \alpha+12 v^{2}-18\right)<g_{\alpha}^{\prime}(1, \alpha)=2(\alpha-$ $6)$, as $4 / 3<\alpha<2, g_{\alpha}^{\prime}(v, \alpha)<0$ and $g(v, \alpha)$ decrease with respect to $\alpha$ and $g(v, \alpha)>g(v, 2)=196 v^{2}-72$ because $4 / 5<v<1, g(v, \alpha)>0$, and $\pi_{A 1}^{N}>\pi_{A 1}^{N S}$.

$\pi_{A 2}^{\mathrm{NS}}-\pi_{A 2}^{N}=((4-\alpha) h(v, \alpha)) /\left(64(12+\alpha)^{2}\right)$, and among them, $\quad h(v, \alpha)=1728 v-576 v^{2}+36 \alpha+288 v \alpha+48 v^{2} \alpha+$ $12 v \alpha^{2}+20 v^{2} \alpha^{2}+v^{2} \alpha^{3}-1296$ and $h_{\alpha}^{\prime}(v, \alpha)=36+288 v+$ $48 v^{2}+24 v \alpha+40 v^{2} \alpha+3 v^{2} \alpha^{2}>0$; therefore, $h(v, \alpha)$ increases with respect to $\alpha$ and $h(v, \alpha)>h(v, 3 / 2)=27\left(648 v-135 v^{2}-\right.$ $368) / 8$ because $4 / 5<v<1, h(v, \alpha)>0$, and $\pi_{A 2}^{\mathrm{NS}}>\pi_{A 2}^{N}$.

$\pi_{A}^{N}-\pi_{A}^{\mathrm{NS}}=\left(v^{2} / 4\right)+\left(\left((6-4 v+\alpha v)^{2}\right) / 64\right)-(45 \alpha /((12+$ $\left.\left.\alpha)^{2}\right)\right)$, setting $l(v, \alpha)=\left(v^{2} / 4\right)+\left((6-4 v+\alpha v)^{2} / 64\right)-(45 \alpha /$ $\left.(12+\alpha)^{2}\right)$ and $l_{v}^{\prime \prime}(v, \alpha)=1 / 2+(4-\alpha)^{2} / 32>0$. Therefore, $l_{v}^{\prime}(v, \alpha)$ increases with respect to $v$ at interval $[4 / 5,1]$ and $l_{v}^{\prime}(v, \alpha)>l_{v}^{\prime}(4 / 5, \alpha)=\left[(\alpha-1 / 4)^{2}+31 / 16\right] / 40>0$; therefore, $l(v, \alpha)$ increases with respect to $v$ at interval $[4 / 5,1]$ and $l(v, \alpha)>l(4 / 5, \alpha)=\left(\left(16272-11256 \alpha+1361 \alpha^{2}+124 \alpha^{3}+\right.\right.$ $\left.\left.4 \alpha^{4}\right) /\left(400(12+\alpha)^{2}\right)\right)>0$, so $\pi_{A}^{N}>\pi_{A}^{\mathrm{NS}}$.

Proof of Theorem 2: $p_{B 2}^{N}-p_{B 2}^{\mathrm{NS}}=(72-48 v-6 \alpha-$ $\left.16 v \alpha-v \alpha^{2}\right) /(8(12+\alpha))$, assuming that $m(v, \alpha)=72-48 v-$ $6 \alpha-16 v \alpha-v \alpha^{2}$ and $m_{v}^{\prime}(v, \alpha)=-48-16 \alpha-\alpha^{2}<0$; therefore, $m(v, \alpha)$ decreases with respect to $v$ at interval $[4 / 5,1]$, $m(v, \alpha)>m(1, \alpha)=24-22 \alpha-\alpha^{2}>0, \quad$ and $\quad 4 / 3<\alpha<2$; therefore, $p_{B 2}^{N}>p_{B 2}^{\mathrm{NS}} ; \pi_{B 2}^{\mathrm{NS}}-\pi_{B 2}^{N}=((168-48 v+26 \alpha-16 v \alpha-$ $\left.\left.v \alpha^{2}\right) p_{\alpha}\right) /\left(128(12+\alpha)^{2}\right)$, setting $n(v, \alpha)=168-48 v+26 \alpha-$ $16 v \alpha-v \alpha^{2}$ and $n_{v}^{\prime}(v, \alpha)=-48-16 \alpha-\alpha^{2}<0$. Therefore, $n(v, \alpha)$ decreases with respect to $v$ at interval $[4 / 5,1]$ and $n(v, \alpha)>n(1, \alpha)=120+10 \alpha-\alpha^{2}>0$; therefore, when $p_{\alpha}>$ $0, \pi_{B 2}^{\mathrm{NS}}>\pi_{B 2}^{N}$.

Proof of Proposition 5: suppose $x_{1}=V_{12}$. Substituting this value into Proposition 1 yields $x_{2}=\left((2+\alpha)\left(1+p_{B 2}\right)-\right.$ $\left.\alpha p_{A 1}-2 p_{A 2}\right) / 4$ and $\pi_{B 2}=p_{B 2}\left[1-\left((2+\alpha)\left(1+p_{B 2}\right)-\alpha p_{A 1}\right.\right.$ $\left.\left.-2 p_{A 2}\right) / 4\right]$. By solving this equation, we have $x_{1}^{*}\left(p_{A 1}\right.$, $\left.p_{A 2}\right)=\left[6+\alpha-(4+\alpha) p_{A 1}+2 p_{A 2}\right] / 4(2+\alpha), x_{2}^{*}\left(p_{A 1}, p_{A 2}\right)=$ $\left(6+\alpha-\alpha p_{A 1}-2 p_{A 2}\right) / 8, p_{B 2}^{*}\left(p_{A 1}, p_{A 2}\right)=\left[2-\alpha+\alpha p_{A 1}+\right.$ $\left.2 p_{A 2}\right] / 2(2+\alpha)$, and $x_{2}^{*}\left(p_{A 1}, p_{A 2}\right)-x_{1}^{*}\left(p_{A 1}, p_{A 2}\right)=(6 \alpha+$ $\left.\alpha^{2}-\alpha^{2} p_{A 1}-2 \alpha p_{A 2}+8 p_{A 1}-8 p_{A 2}\right) / 8(2+\alpha)$.

Firm 1's profit in the second stage is $\pi_{A 2}=p_{A 2}$ $\left(x_{2}^{*}\left(p_{A 1}, p_{A 2}\right)-x_{1}^{*} p\left({ }_{A 1}, p_{A 2}\right)\right)=p_{A 2}\left(\left(6 \alpha+\alpha^{2}-\alpha^{2} p_{A 1}-2 \alpha\right.\right.$ $\left.\left.p_{A 2}+8 p_{A 1}-8 p_{A 2}\right) /(8(2+\alpha))\right)$.

By solving this equation, we have $p_{A 2}^{*}\left(p_{A 1}\right)=[6 \alpha+$ $\left.\alpha^{2}+8 p_{A 1}-\alpha^{2} p_{A 1}\right] / 4(4+\alpha), \quad x_{2}^{*}\left(p_{A 1}\right)-x_{1}^{*}\left(p_{A 1}\right)=[\alpha(6+$ $\left.\alpha)-\left(-8+\alpha^{2}\right) p_{A 1}\right] / 16(2+\alpha)$, and $\pi_{A 2}^{*}\left(p_{A 1}\right)=p_{A 2}^{*}\left(p_{A 1}\right)$ $\left(x_{2}^{*}\left(p_{A 1}\right)-x_{1}^{*}\left(p_{A 1}\right)\right)=\left(\alpha(6+\alpha)+\left(8-\alpha^{2}\right) p_{A 1}\right)^{2} / 64(2+\alpha)$ $(4+\alpha)$.

Firm 1's total profit in the two stages is $\pi_{A}=p_{A 1}((48+$ $\left.\left.26 \alpha+3 \alpha^{2}-\left(24+16 \alpha+3 \alpha^{2}\right) p_{A 1}\right) /(8(2+\alpha)(4+\alpha))\right)+((\alpha$ $\left.\left.(6+\alpha)+\left(8-\alpha^{2}\right) p_{A 1}\right)^{2} /(64(2+\alpha)(4+\alpha))\right)$.

By solving this equation, we have $p_{A 1}^{*}=((2+\alpha)(96+$ $\left.\left.28 \alpha-4 \alpha^{2}-\alpha^{3}\right)\right) /\left((4+\alpha)\left(32+24 \alpha+4 \alpha^{2}-\alpha^{3}\right)\right), \quad p_{A 2}^{*}=$ $\left(384+496 \alpha+216 \alpha^{2}+42 \alpha^{3}+3 \alpha^{4}\right) /\left((4+\alpha)^{2}(32+24 \alpha+\right.$ $\left.\left.4 \alpha^{2}-\alpha^{3}\right)\right), \quad p_{B 2}^{*}=\left(896+1264 \alpha+584 \alpha^{2}+54 \alpha^{3}-23 \alpha^{4}-\right.$ $\left.4 \alpha^{5}\right) /\left((2+\alpha)(4+\alpha)^{2}\left(32+24 \alpha+4 \alpha^{2}-\alpha^{3}\right)\right)$, and $\left(\left(p_{A 2}^{*}-\right.\right.$ $\left.\left.p_{A 1}^{*}\right) / \alpha\right)<0$. This is a contradiction; therefore, $x_{1}=V_{11}$.

Proof of Proposition 6: similar to Proposition 2 and 4, after solving function (4), we have $p_{A 1}^{S}=3(8-\alpha) \alpha / v_{\alpha}$. Substituting $p_{A 1}^{S}=3(8-\alpha) \alpha / v_{\alpha}$ into Proposition 1 to obtain each decision parameter, $v_{\alpha}=16+16 \alpha-\alpha^{2}$ increases at interval $4 / 3<\alpha<2$ and $v_{\alpha}>37.75>0$. 
Proof of Theorem 3:

(1) $x_{1}^{\mathrm{NS}}-x_{1}^{S}=\left(\left(15\left(16-\alpha^{2}\right)\right) /(2(12+\alpha)(16+16 \alpha-\right.$ $\left.\left.\left.\alpha^{2}\right)\right)\right)>0$; therefore, $x_{1}^{\mathrm{NS}}>x_{1}^{S}$. $x_{2}^{\mathrm{NS}}-x_{2}^{S}=((15 \alpha$ $\left.(4-\alpha)) /\left((12+\alpha)\left(16+16 \alpha-\alpha^{2}\right)\right)\right)>0$; therefore, $x_{2}^{\mathrm{NS}}>x_{2}^{S} . \Delta x^{S}-\Delta x^{\mathrm{NS}}=\left(\left(15(\alpha-4)^{2}\right) /(2(12+\alpha)(16\right.$ $\left.\left.\left.+16 \alpha-\alpha^{2}\right)\right)\right)>0$; therefore, $\Delta x^{S}>\Delta x^{\mathrm{NS}}$.

(2) $p_{A 1}^{S}-p_{A 1}^{\mathrm{NS}}=(60(4-\alpha) \alpha) /((12+\alpha)(16+16 \alpha-$ $\left.\left.\alpha^{2}\right)\right)>0$; therefore, $\quad p_{A 1}^{S}>p_{A 1}^{\mathrm{NS}} . \quad p_{A 2}^{S}-p_{A 2}^{\mathrm{NS}}=$ $\left(\left(15 \alpha(\alpha-4)^{2}\right) /\left(2(12+\alpha)\left(16+16 \alpha-\alpha^{2}\right)\right)\right)>0$; therefore, $p_{A 2}^{S}>p_{A 2}^{N S}$.

(3) $\pi_{A 1}^{N S}-\pi_{A 1}^{S}=\left(\left(45 \alpha(4-\alpha)^{2}\left(64+4 \alpha+\alpha^{2}\right)\right) /(2(12+\right.$ $\left.\left.\alpha)^{2}\left(16+16 \alpha-\alpha^{2}\right)^{2}\right)\right)>0$; therefore, $\pi_{A 1}^{\mathrm{NS}}>\pi_{A 1}^{S} \cdot \pi_{A 2}^{S}-$ $\pi_{A 2}^{\mathrm{NS}}=\left(\left(45 \alpha(4-\alpha)^{2}\left(208+88 \alpha-3 \alpha^{2}\right)\right) /\left(4(12+\alpha)^{2}\right.\right.$ $\left.\left.\left(16+16 \alpha-\alpha^{2}\right)^{2}\right)\right)>0$; therefore, $\pi_{A 2}^{S}>\pi_{A 2}^{\mathrm{NS}} . \pi_{A}^{S}-$ $\pi_{A}^{\mathrm{NS}}=\left(\left(225 \alpha(\alpha-4)^{2}\right) /\left(4(12+\alpha)^{2}\left(16+16 \alpha-\alpha^{2}\right)\right)\right)$ $>0$; therefore, $\pi_{A}^{S}>\pi_{A}^{\mathrm{NS}}$.

Proof of Theorem 4:

(1) $p_{B 2}^{S}-p_{B 2}^{\mathrm{NS}}=3 \alpha(8-\alpha) / 2 v_{\alpha}>0$; therefore, $p_{B 2}^{S}>p_{B 2}^{\mathrm{NS}}$

(2) $\pi_{B 2}^{S}-\pi_{B 2}^{\mathrm{NS}}=30 \alpha(4-\alpha)\left(96+188 \alpha+11 \alpha^{2}-2 \alpha^{3}\right) /(12+$ $\alpha)^{2} v_{\alpha}^{2}>0$; therefore, $\pi_{B 2}^{S}>\pi_{B 2}^{\mathrm{NS}}$

Proof of Corollary 1:

(1) It is easy to determine from Theorems 1 and 3.

(2) $p_{A 1}^{S}-p_{A 1}^{N}=\left(16 v-48 \alpha+16 v \alpha+6 \alpha^{2}-v \alpha^{2}\right) /(2(16+$ $\left.\left.16 \alpha-\alpha^{2}\right)\right)$, setting $r(v, \alpha)=48 \alpha-16 v \alpha-6 \alpha^{2}+v \alpha^{2}-$ $16 v$ and $r_{v}^{\prime}(v, \alpha)=-\left(16+16 \alpha-\alpha^{2}\right)<0$. Therefore, $r(v, \alpha)$ decreases with respect to $v$ at interval $[4 / 5,1]$; therefore, $r(v, \alpha)>r(1, \alpha)=-16+32 \alpha-5 \alpha^{2}>0$ and $p_{A 1}^{S}>p_{A 1}^{N}$, and then, from Theorem 1, when $12 v-6 \alpha+v \alpha>0, p_{A 1}^{N S}<p_{A 1}^{N}<p_{A 1}^{S}$.

$p_{A 2}^{N}-p_{A 2}^{S}=\left(\left((4-\alpha)\left(24-16 v+12 \alpha-16 v \alpha+v \alpha^{2}\right)\right) /(4\right.$ $\left.\left.\left(16+16 \alpha-\alpha^{2}\right)\right)\right)$, setting $s(v, \alpha)=24-16 v+12 \alpha-16 v \alpha+$ $v \alpha^{2}$ and $s_{v}^{\prime}(v, \alpha)=-\left(16+16 \alpha-\alpha^{2}\right)<0$. Therefore, $s(v, \alpha)$ decreases with respect to $v$ at interval $[4 / 5,1]$ and $s(\nu, \alpha)>s(1, \alpha)=\alpha^{2}-4 \alpha+8=(\alpha-2)^{2}+4>0$; therefore, $p_{A 2}^{N}>p_{A 2}^{S}$, and from Proposition $3, p_{A 2}^{N}>p_{A 2}^{S}>p_{A 2}^{\mathrm{NS}}$.

(3) From Theorems 1 and 3 , we find that $\pi_{A 1}^{S}<$ $\pi_{A 1}^{\mathrm{NS}}<\pi_{A 1}^{N}, \pi_{A 2}^{N}<\pi_{A 2}^{\mathrm{NS}}<\pi_{A 2}^{S}$.

Setting $t(v, \alpha)=\pi_{A}^{S}-\pi_{A}^{N}=((9(8-\alpha) \alpha(3 \alpha-4)) /(2(16+$ $\left.\left.\left.16 \alpha-\alpha^{2}\right)^{2}\right)\right)+\left(\left(9 \alpha(12+\alpha)^{2}\right) /\left(4\left(16+16 \alpha-\alpha^{2}\right)^{2}\right)\right)-\left(v^{2} /\right.$ $4)-\left((6-4 v+\alpha v)^{2} / 64\right), \quad t_{v}^{\prime \prime}(v, \alpha)=-1 / 2-(4-\alpha)^{2} / 32<0$. Therefore, $t_{v}^{\prime}(v, \alpha)$ decreases with respect to $v$ at interval $[4 / 5,1]$ and $t_{v}^{\prime}(v, \alpha)<t_{v}^{\prime}(4 / 5, \alpha)=-\left(2 \alpha^{2}-\alpha+4\right) / 80<0$ and $t(v, \alpha)$ decreases with respect to $v$ at interval $[4 / 5,1]$; $t(v, \alpha)>t(1, \alpha)=\left(\left(\left(20-16 \alpha+\alpha^{2}\right)\left(-16+4 \alpha+\alpha^{2}\right)\right) /(64\right.$ $\left.\left.\left(16+16 \alpha-\alpha^{2}\right)\right)\right)>0$; therefore, $\pi_{A}^{S}>\pi_{A}^{N}$, and from Theorem $1, \pi_{A}^{S}>\pi_{A}^{N}>\pi_{A}^{\mathrm{NS}}$.

Proof of Corollary 2:

(1) $p_{B 2}^{S}-p_{B 2}^{N}=\left(64 v+80 v \alpha-6 \alpha^{2}+12 v \alpha^{2}-v \alpha^{3}-96\right) /$ $\left(8\left(16+16 \alpha-\alpha^{2}\right)\right)$, setting $w(v, \alpha)=64 v+80 v \alpha-$ $6 \alpha^{2}+12 v \alpha^{2}-v \alpha^{3}-96$ and $w_{v}^{\prime}(v, \alpha)=64+\alpha(80+$ $\left.12 \alpha-\alpha^{2}\right)>0$ and $w(v, \alpha)$ increases with respect to $v$ at interval $[4 / 5,1] ; w(v, \alpha)>w(1, \alpha)=16(5 \alpha-2)+$ $\alpha^{2}(6-\alpha)>0$; therefore, $p_{B 2}^{S}>p_{B 2}^{N}$, and thus, from Theorem 1, $p_{B 2}^{S}>p_{B 2}^{N}>p_{B 2}^{N S}$.

(2) This proof is easy to be determined from Theorems 2 and 4 .

\section{Data Availability}

The data used to support the findings of this study are included within the article.

\section{Conflicts of Interest}

The authors declare that they have no conflicts of interest.

\section{Acknowledgments}

This work received support from, the subproject of the National Key Natural Science Project (71832001), the Project of Humanities and Social Sciences of the Ministry of Education (18YJA630153), and the Shanghai Social Science Project (2017BGL018).

\section{References}

[1] M. Katz and C. Shapiro, "Technology adoption in the presence of network externalities," Journal of Political Economy, vol. 94, no. 4, pp. 822-841, 1985.

[2] B. Bensaid and J.-P. Lesne, "Dynamic monopoly pricing with network externalities," International Journal of Industrial Organization, vol. 14, no. 6, pp. 837-855, 1996.

[3] T. Doganoglu, Dynamic Price Competition with Consumption Externalities, Vol. 5, Kluwer Academic Publishers, Alphen, Netherlands, 2003.

[4] X. Li and H.-M. Chen, "Study on pricing strategy choice of firms with network externality," Journal of Management Science, vol. 9, no. 6, pp. 23-30, 2006, in Chinese.

[5] A. Hajji, R. Pellerin, P.-M. Léger, A. Gharbi, and G. Babin, "Dynamic pricing models for ERP systems under network externality," International Journal of Production Economics, vol. 135, no. 2, pp. 708-715, 2012.

[6] R. Bayer and M. Chan, "Network externalities, demand inertia and dynamic pricing in an experimental oligopoly market," Economic Record, vol. 83, no. 263, pp. 405-415, 2008.

[7] X. Li, G. Nan, M. Li et al., "Optimal pricing strategy for new entrants with free base products," Journal of Systems Engineering, vol. 33, no. 1, pp. 13-22, 2018, in Chinese.

[8] B. Jing, "Network externalities and market segmentation in a monopoly," Economics Letters, vol. 95, no. 1, pp. 7-13, 2007.

[9] M. Aoyagi, Bertrand Competition under Network Externalities, Osaka University, Suita, Japan, 2014, https://ssrn.com/ abstract $=2320347$.

[10] S. Mouakket and Y. Sun, "Examining factors that influence information disclosure on social network sites from the perspective of network externalities," Industrial Management \& Data Systems, vol. 119, no. 4, pp. 774-791, 2019.

[11] H. Xu, "Pricing model with network externalities," Advances in Applied Mathematics, vol. 7, no. 2, pp. 189-194, 2018.

[12] K. Choi and D. J. Lee, "Welfare-improving vertical separation with network externality," Economics Letters, vol. 151, pp. 115-118, 2017. 
[13] O. Bountali and A. Economou, "Strategic customer behavior in a two-stage batch processing system," Queueing Systems, vol. 93, no. 1-2, pp. 3-29, 2019.

[14] W. Elmaghraby and P. Keskinocak, "Dynamic pricing in the presence of inventory considerations: research overview, current practices, and future directions," Management Science, vol. 49, no. 10, pp. 1287-1309, 2003.

[15] X. Liu and P. Huang, "Optimal dynamic pricing and inventory policy under strategic customers," Journal of Management Science, vol. 12, no. 5, pp. 18-26, 2009, in Chinese.

[16] Y. Aviv and A. Pazgal, "Optimal pricing of seasonal products in the presence of forward-looking consumers," Manufacturing \& Service Operations Management, vol. 10, no. 3, pp. 339-359, 2008.

[17] S. Tie-bo, X. Zhong, C. Wei-hong et al., "R\&D investment or advertising investment?-choice of strategic behavior of firms in poor performance," RङD Management, vol. 30, no. 1, pp. 12-21, 2018, in Chinese.

[18] N. Surasvadi, C. S. Tang, and G. Vulcano, "Using contingent markdown with reservation to profit from strategic consumer behavior," Production and Operations Management, vol. 26, no. 12, pp. 2226-2246, 2017.

[19] M. M. Wei and F. Zhang, "Advance selling to strategic consumers: preorder contingent production strategy with advance selling target," Production \& Operations Management, vol. 27, no. 7, pp. 1221-1235, 2018.

[20] S. Colombo, "Network externalities and differentiation in an entry model," Economics Bulletin, vol. 31, no. 1, pp. 75-84, 2011.

[21] Z. Liu, M. Li, and J. Kou, "Selling information products: sale channel selection and versioning strategy with network externality," International Journal of Production Economics, vol. 166, pp. 1-10, 2015.

[22] T. M. Whitin, "Inventory control and price theory," Management Science, vol. 2, no. 1, pp. 61-80, 1955.

[23] L. Young, "Price, inventory and the structure of uncertain demand," New Zealand Operation Research, vol. 6, no. 2, pp. 157-177, 1978.

[24] L. H. Polatoglu, "Optimal order quantity and pricing decisions in single period inventory systems," International Journal of Producton Economics, vol. 23, no. 1-3, pp. 175-185, 1991.

[25] A. Federgruen and A. Heching, "Combined pricing and Inventory control under uncertainty," Operations Research, vol. 47, no. 3, pp. 454-475, 1999.

[26] D. Dana and N. C. Petruzzi, The Newsvendor Model with Endogenous Demand, Working Paper, Kellog Graduate School of Management, Northwestern University, Evanston, IL, USA, 2001.

[27] Z. Cao, X. Chen, X. Hu, and C. Wang, "Approximation algorithms for pricing with negative network externalities," Journal of Combinatorial Optimization, vol. 33, no. 2, pp. 681-712, 2017. 